\title{
Leaf Anatomical Changes Induced by Paclobutrazol Tree Growth Regulator in Cherrybark Oak
}

\author{
Yadong Qi ${ }^{1,2}$, Vanessa A. Ferchaud ${ }^{2}$, Kit L. Chin ${ }^{2}$ and Ying Xiao ${ }^{3}$ \\ 1. Urban Forestry Program, Southern University and A\&M College, Baton Rouge, LA \\ 2. Southern University Agricultural Research and Extension Center, Baton Rouge, LA, \\ 3. Department of Biological Sciences, Louisiana State University, Baton Rouge, LA
}

Paclobutrazol (PBZ) is a commercial growth retardant developed for reducing tree growth along streets and under utility power lines. Our previous studies indicated PBZ treated cherrybark oak (Quercus falcata var. pagodafoila L.) exhibited smaller and thicker leaves, shorter leaf petioles, higher chlorophyll content, higher light absorbance, darker green foliage, and more compact crowns with improved gas exchange rates; and PBZ application significantly reduced the tree height and diameter growth in cherrybark oak [1, 2, 3, 4]. The improved physiological performance and reduced tree size can help enhance tree vigor and lower the pruning associated maintenance cost at the same time. Thus, applied properly, PBZ can be used as an effective tool in urban and community tree management. This paper took a closer look at the leaf anatomical changes induced by PBZ tree growth regulator in cherrybark oak, which is one of the major oak species and popular shade trees in the Southern USA.

The experiment was initiated with six-year old cherrybark oak, grown in a mixed stand $(2.7 \mathrm{~m} \mathrm{x} 2.7 \mathrm{~m}$ spacing) at the Horticulture Farm of Southern University, Baton Rouge, Louisiana, USA. Fourteen trees per species were selected. One-half of the trees were treated with PBZ and the other half was an untreated control. PBZ, formulated as Profile 2SC, was applied in a water suspension by soil drench to cherrybark oak trees at 9.6 g active ingredient (a. i.) per tree in April, 1997 and no additional treatment was applied thereafter. Leaf surface (radial) and transverse (cross-section) anatomy was studied for sunexposed mature leaves using a scanning electron microscope (SEM) (Cambridge Stereoscan 260 Scanning Electron Microscope) in June 2001. Fresh leaves were sectioned through the main veins and the middle sections were selected with six replicates per treatment. The leaf sections were fixed in FAA solution (ethanol (100\%): glacial acetic acid: formaldehyde (37\%): water, 50:5:10:35 v/v), coated with a thin layer of gold after dehydration and critical point drying, and observed through the SEM.

The SEM graphs of leaf surfaces (Fig. 1) and transverse sections (Fig. 2) revealed remarkable differences between control and treated cherrybark oak trees. Comparing to control (Fig. 1, a), the PBZ application greatly increased the trichome density on the abaxial surface of the leaf (Fig. 1, b). PBZ treatment also induced thicker leaf cross section and more compacted palisade tissue (Fig. 2, b) than control (Fig. 2, a). While the radial growth of palisade cells was suppressed, transverse growth of these cells appeared to be stimulated and longer; thus resulting much thicker palisade layer in PBZ treated leaves (Fig. 2, b). This explains why the leaf surface area was significantly reduced while the total leaf thickness was significantly enhanced by PBZ treatment in our previous studies [2, 3]. The thickened leaves of PBZ treated trees exhibited higher chlorophyll content and gas exchange rates per unit of leaf area, thus improving the tree vigor [2]. In addition, the enhanced trichome density in PBZ treated trees could be beneficial to leaves by serving as physical barriers to biotic invasion and a means by which the boundary layer resistance is increased to reduce moisture loss under dry and stressed weather conditions. In conclusion, the leaf anatomical modification induced by PBZ treatment could make trees more stress tolerant. [5] 


\section{References:}

[1] Y Qi et al, Proc of $41^{\text {st }}$ Annual Meeting of Plant Growth Regulation Society of America (2014) 6pp.

[2] Y Qi et al, Proc of $29^{\text {th }}$ Annual Meeting of PGRSA (2002) p123-128.

[3] Y Qi et al, Proc of $28^{\text {th }}$ Annual Meeting of PGRSA (2001) p107-113.

[4] Y Qi et al, Proc of $27^{\text {th }}$ Annual Meeting of PGRSA (2000) p260-265.

[5] The authors acknowledge support from USDA-NIFA McIntire-Stennis Funds and USDA-NIFA CBGP Grant to Southern University Agricultural Research and Extension Center.

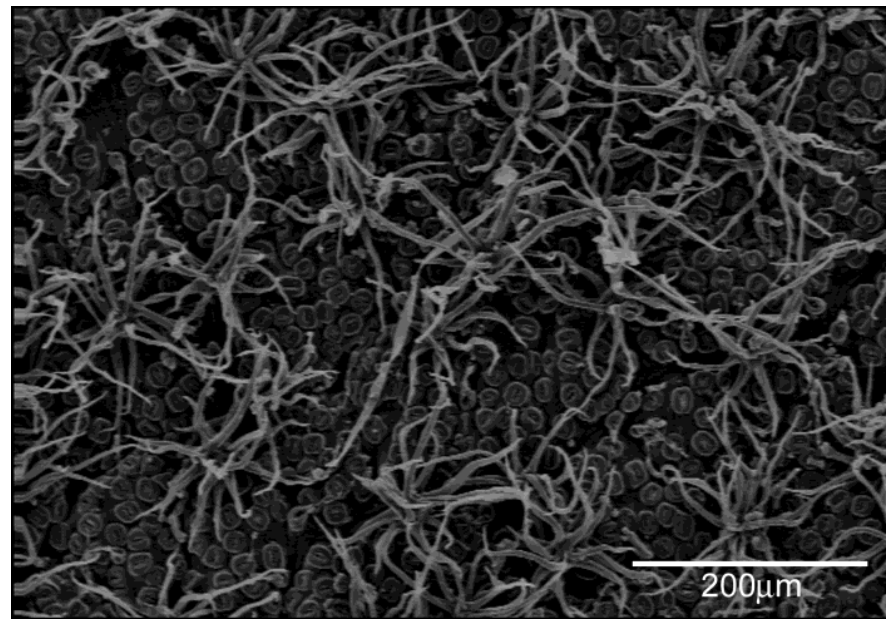

a

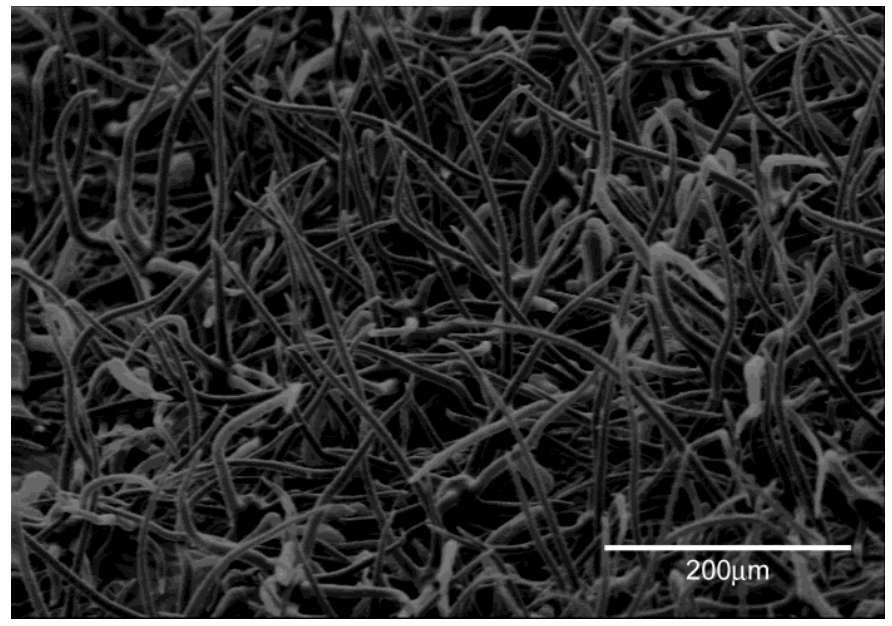

b

Figure 1. Leaf abaxial surfaces of cherrybark oak under normal (control) condition (a) and paclobutrazol treatment (b), showing paclobutrazol greatly enhanced trichome density on the abaxial surface.

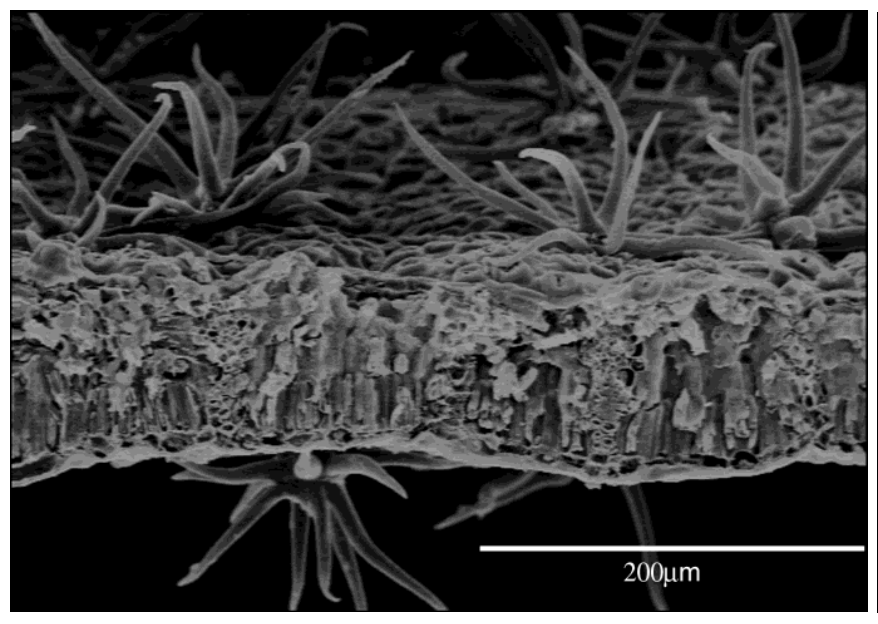

a

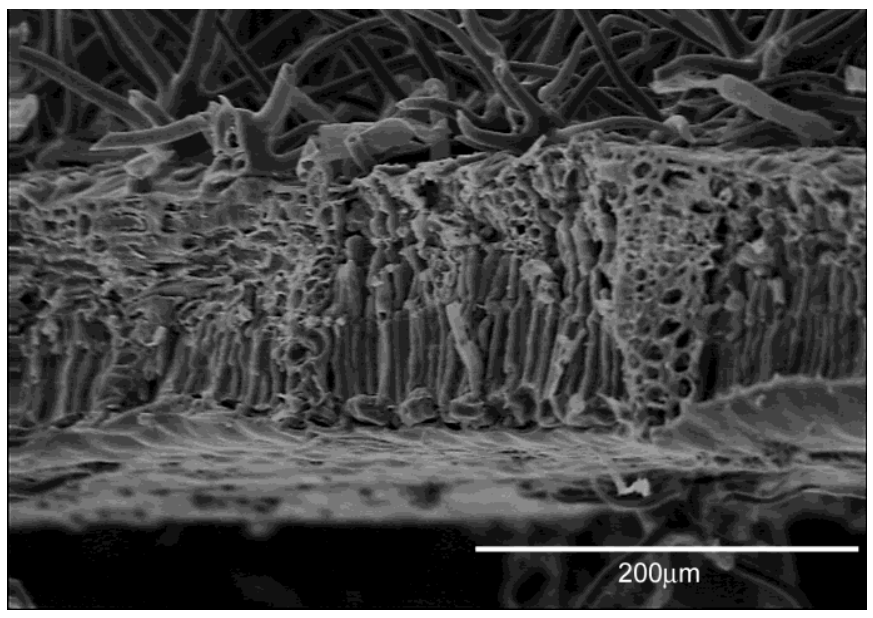

$\mathrm{b}$

Figure 2. Leaf transverse views of cherrybark oak under normal (control) condition (a) and paclobutrazol treatment (b), showing paclobutrazol treatment increased total leaf thickness with a thicker palisade layer and higher density of the trichome layer on the abaxial leaf surface. 